NOTA CIENTÍFICA

\title{
DIAGNÓSTICO BIOCLIMÁTICO PARA MESORREGIÃO METROPOLITANA DE CURITIBA - PR
}

\section{DIAGNOSIS FOR BIOCLIMATIC MESOREGION METROPOLITAN AREA OF CURITIBA}

\author{
Eduardo Teixeira da SILVA ${ }^{1}$ \\ Daniel Guedes LEITE ${ }^{2}$ \\ Flavio Manabu YURI ${ }^{2}$ \\ Francine da Silva Guerellus NERY² \\ Josiane Crystina Costa REGO² \\ Roberta de Azevedo ZANATTA2 \\ Samuel Augusto dos SANTOS ${ }^{2}$ \\ Vinicius Vieira MOURA ${ }^{2}$
}

\begin{abstract}
RESUMO
O objetivo deste trabalho é analisar dados climatológicos da mesorregião Metropolitana de Curitiba do Estado do Paraná com intuito de relacioná-los com as exigências bioclimáticas para a produção de aves, para verificar a viabilidade da criação, como também, servir de orientação a avicultores e futuros criadores na implantação de sistemas de controle ambiental utilizando a metodologia proposta por ABREU e ABREU (2001). O diagnóstico foi realizado com os dados climáticos, obtidos das normais climatológicas fornecidos pelo Instituto Agronômico do Paraná (IAPAR) das seguintes microrregiões: Antonina, Cerro Azul, Guaraqueçaba, Lapa, Morretes e Pinhais; os valores da Temperatura Média do Ar Compensada e Umidade Relativa foram utilizados para comparar com as condições de conforto térmico para aves, em função da idade das mesmas. As comparações realizadas em cada microrregião mostraram a necessidade de corrigir o microclima dos galpões para alcançar condições ideais para produção de aves. As microrregiões de Antonina, Lapa e Pinhais não apresentam condições ideais para desenvolvimento da atividade durante todas as fases de vida, portanto, para tal exige investimentos em controle ambiental, ou seja, aquecimento contínuo do galpão de criação; As microrregiões de Cerro Azul e Guaraqueçaba exigem sistemas de controle ambiental, aquecimento e principalmente resfriamento na última semana de vida.
\end{abstract}

Palavras-chave: conforto térmico; bioclimatologia; avicultura.

\begin{abstract}
The objective of this work is to analyze climatology data of the Metropolitan meso-region of Curitiba, Paraná State with objective of relate them with the demands bioclimáticas for the production of poultry, to verify the viability of the creation, as well as, to serve of orientation to poultry keepers and future poultry keepers in the implantation of systems of environmental control. The analysis was accomplished with the climatic data supplied by climatology normal IAPAR of the following microregion: Antonina, Cerro Azul, Guaraqueçaba, Lapa, Morretes and Pinhais; the values of the Medium Temperature of the Compensated Air and Relative Humidity, they were used to compare with the conditions of thermal comfort for poultry, in function of the age of the same ones ABREU e ABREU (2001). The comparisons accomplished in each micro-region showed the need to correct the climate of the sheed to reach ideal conditions for production of poultry. The micro-region of Antonina, Lapa and Pinhais not present ideal conditions for development of the activity during whole you make them of life, therefore, for such it demands investments in environmental control, that is to say continuous heating of the creation sheed; The microregions of Cerro Azul and Guaraqueçaba demand systems of environmental control, heating and mainly cooling in the last week of life.
\end{abstract}

Key-words: comfort thermal; climatology; poultry.

\footnotetext{
${ }^{1}$ Engenheiro Agrícola, Doutor, UFPR, Depto. de Solos e Eng. Agrícola, Prof. Adjunto, R dos Funcionários, 1540 CEP 80035-050, Curitiba, PR. eduardo@ufpr.br

${ }^{2}$ Alunos do Curso de Zootecnia - Universidade Federal do Paraná - SCA - Estagiários Departamento de Solos e Engenharia Agrícola
} 
SILVA, E.T. et. al. Diagnóstico bioclimático para mesorregião...

\section{INTRODUÇÃO}

Nos últimos anos, o Brasil tornou-se o maior exportador de carne de frango do mundo. Relacionado ao volume acumulado de 12 meses, ate o mês de janeiro de 2008, foram exportados cerca de 3,3 milhões de toneladas de carne, dos 10,4 milhões produzidos entre fevereiro de 2007 e janeiro de 2008, mantendo o país em terceiro lugar na produção mundial (PRODUCAOANIMALAVICULTURA, 2008). Estes resultados superaram em 100 mil toneladas as projeções da ABEF (2006) para o ano de 2007. Tais números indicam uma projeção favorável para o Brasil neste ano, com previsão de aumento de $7 \%$ nas exportações, sendo que $75 \%$ das exportações mundiais concentram se no Brasil e nos Estados Unidos. Ate dezembro de 2007 , houve um aumento de $22,8 \%$ nas exportações de carne de frango, sendo os principais mercados deste produto a Arábia Saudita, Japão, Rússia e Hong Kong, somado a ampliação de $31,9 \%$ dos mercados para a União Européia de diversos produtos, dentre eles a carne de frango (SECEX, 2008). Isso chama a atenção à responsabilidade de se manter uma alta produtividade aliada a qualidade do produto, como intuito de se consolidar no topo do ranking do mercado mundial.

O conforto térmico é caracterizado pela sensação de bem estar ocasionada por um ambiente em função da ação conjunta dos fatores temperatura, umidade relativa, aeração e radiação solar. Assim, há uma faixa efetiva de ocorrência de tais fatores, para o qual o animal está em conforto térmico, ou seja, não está estressado nem por frio nem por calor, é chamada "zona de conforto térmico". Nestas condições, o esforço termorregulatório do animal é mínimo e o desempenho em qualquer atividade é otimizado.

Até pouco tempo atrás o conforto térmico era considerado como problema secundário dentro da produção animal, figurando em segundo plano perante os avanços constantes da genética, nutrição e sanidade. No entanto, à medida que a tecnologia avança e os níveis de confinamento tornam-se um problema, a ambiência animal surge como um assunto de extrema importância, principalmente no que diz respeito à redução de perdas dentro dos processos produtivos e das exigências quanto às boas práticas de manejo e de bem-estar animal.

É praticamente impossível imaginar um ambiente que não exerça nenhum tipo de estresse aos animais. Mesmo que este seja cuidadosamente planejado, sempre haverá algum elemento que não permitirá que o animal se encontre totalmente em situação de conforto. Dentre estes elementos, que poderão causar estresse aos animais, estão as variáveis ambientais.

LIN et al. (2006) classificam os elevados valores de temperatura como um dos mais importantes agentes causadores de estresse dentro da produção avícola, sendo o estresse térmico resultante das interações entre temperatura do ar, umidade relativa, radiação e velocidade do vento, onde a temperatura possui maior peso.

Segundo os mesmos autores, é sabido que as linhagens de frangos de corte são particularmente muito sensíveis às condições de estresse térmico, pois a taxa de produção de calor metabólico aumenta com o desenvolvimento das aves, mas sua capacidade de dissipação de calor corporal não acompanha essa evolução. Sendo assim, ambientes com altos valores de temperaturas resultarão em problemas de desempenho e até mesmo em morte das aves.

A faixa térmica onde 0 animal se encontra em conforto é aquela em que a produção ou dissipação de calor é mínima ou a termoneutralidade é ajustada através do saldo de perda de energia térmica para o ambiente sem auxílio de algum mecanismo de conservação ou dissipação de calor. SILVA et al. (2000) descreve a zona de conforto térmico como aquela onde os animais não necessitam de ativação de qualquer mecanismo de controle de termorregulação, seja ele químico ou físico.

Portanto, construir instalações adequadas ao clima e que permitam a manutenção de temperatura, umidade relativa, velocidade do ar, em limites que proporcionam ambiente ideal no interior do galpão de acordo com as exigências das aves, sem aumento dos custos de produção, tem sido grande desafio. O objetivo deste trabalho foi analisar dados climatológicos da mesorregião Metropolitana de Curitiba do Estado do Paraná com intuito de relacioná-los com as exigências bioclimáticas para a produção de aves, para verificar a viabilidade da criação, como também, servir de orientação a avicultores e futuros criadores na implantação de sistemas de controle ambiental utilizando a metodologia proposta por ABREU e ABREU (2001).

\section{MATERIAL E MÉTODOS}

O Estado do Paraná localiza-se na Região Sul do País, ocupando uma área de 199.725 km², que corresponde a 2,3\% da superfície total do Brasil, situando-se entre os meridianos de $48^{\circ} 30^{\prime}$ e $54^{\circ}$ 30 ' de longitude a oeste de Greenwich e os paralelos de $22^{\circ} 30^{\prime}$ e $26^{\circ} 30^{\prime}$ de latitude sul. O Paraná está dividido em 39 microrregiões e 10 mesorregiões (a partir de $1^{\circ}$ de janeiro de 1990, foi aprovada a nova "Divisão Regional do Brasil em Mesorregiões e Microrregiões Geográficas", através da resolução PR número 51, de 31/07/1989), para este trabalho foi utilizada a mesorregião: Metropolitana de Curitiba. Foram selecionadas seis estações agrometeorológicas, uma em cada uma das seguintes microrregiões: Antonina, Cerro Azul, Guaraqueçaba, Lapa, Morretes e Pinhais. A Tabela 1 apresenta a caracterização das microrregiões. A análise da temperatura média e umidade relativa foi realizada a partir dos dados climáticos obtidos das normais climatológicas fornecidos pelo Instituto Agronômico do Paraná - Área de Ecofisiologia (IAPAR). 
SILVA, E.T. et. al. Diagnóstico bioclimático para mesorregião...

TABELA 1 - Caracterização das microrregiões analisadas.

\begin{tabular}{lcccccc}
\hline & & & & & \multicolumn{2}{c}{ Dados climáticos } \\
\hline Microrregião & Longitude & Latitude & Altitude $(\mathrm{m})$ & Área $\left(\mathrm{km}^{2}\right)$ & Ano início & Ano fim \\
\hline Antonina & $25^{\circ} 13^{\prime} \mathrm{S}$ & $48^{\circ} 48^{\prime} \mathrm{W}$ & 60 & 845,853 & 1987 & 1999 \\
Cerro Azul & $24^{\circ} 49^{\prime} \mathrm{S}$ & $59^{\circ} 15^{\prime} \mathrm{W}$ & 360 & $1.153,238$ & 1987 & 1998 \\
Guaraqueçaba & $25^{\circ} 16^{\prime} \mathrm{S}$ & $48^{\circ} 32^{\prime} \mathrm{W}$ & 40 & $2.317,024$ & 1987 & 2003 \\
Lapa & $25^{\circ} 47^{\prime} \mathrm{S}$ & $49^{\circ} 46^{\prime} \mathrm{W}$ & 910 & $2.145,352$ & 1988 & 2004 \\
Morretes & $25^{\circ} 30^{\prime} \mathrm{S}$ & $48^{\circ} 49^{\prime} \mathrm{W}$ & 59 & 662,758 & 1987 & 2003 \\
Pinhais & $25^{\circ} 25^{\prime} \mathrm{S}$ & $49^{\circ} 46^{\prime} \mathrm{W}$ & 930 & 60,796 & 1987 & 1998 \\
\hline
\end{tabular}
variáveis:

Para o estudo foram utilizadas as seguintes - Média da temperatura do ar compensada ( $t$ med);

- Umidade relativa do ar (UR).

Estes valores foram utilizados para comparar com as condições de conforto térmico ideais para aves, em função da sua idade em semanas (Tabela 2). Para comparar as exigências das aves com os valores climáticos das microrregiões foi adotada a seguinte simbologia ABREU e ABREU (2001):

I - Temperaturas inferiores à zona de conforto;

C - Temperaturas confortáveis à zona de conforto;

$\mathrm{S}$ - Temperaturas superiores à zona de conforto;

I - Umidade relativa inferior à zona de conforto;

$\underline{C}$ - Umidade relativa confortável à zona de conforto; $\underline{\underline{S}}$ - Umidade relativa superior a exigidos pelas aves;

TABELA 2 - Valores ideais de temperatura, umidade relativa do ar e do índice de temperatura e umidade (ITU), em função da idade das aves.

\begin{tabular}{ccc}
\hline $\begin{array}{c}\text { Idade } \\
\text { (Semanas) }\end{array}$ & Temperatura $\left({ }^{\circ} \mathrm{C}\right)$ & $\begin{array}{c}\text { Umidade Relativa do } \mathrm{Ar} \\
(\%)\end{array}$ \\
\hline 1 & $32-35$ & $60-70$ \\
2 & $29-32$ & $60-70$ \\
3 & $26-29$ & $60-70$ \\
4 & $23-26$ & $60-70$ \\
5 & $20-23$ & $60-70$ \\
6 & 20 & $60-70$ \\
7 & 20 & $60-70$ \\
\hline
\end{tabular}

Fonte: ABREU e ABREU (2001)

\section{RESULTADOS E DISCUSSÃO}

\section{Microrregião de Antonina}

Analisando as Tabelas 2 e 3 correspondente à temperatura e umidade relativa do ar ideais para criação de aves e a temperatura média e umidade relativa média; podemos verificar que na sexta semana de idade, somente nos meses de janeiro, fevereiro e dezembro a temperatura proporcionou conforto térmico para as aves. Nos demais meses do ano a temperatura ambiente foi inferior ao exigido pelas aves em todas as fases de criação. Portanto existe a necessidade de sistemas de aquecimento do galpão durante todos os meses do ano e em todas as fases do ciclo de vida. Com relação à umidade relativa média, podemos verificar que apresenta valores superiores aos ideais em todas as fases do ciclo de vida das aves e durante todo o ano.

\section{Microrregião de Cerro Azul}

Analisando as Tabelas 2 e 4 correspondente à temperatura e umidade relativa do ar ideais para criação das aves e a temperatura média e umidade relativa podemos verificar, na quarta semana de idade somente nos meses de janeiro, fevereiro, março e dezembro a temperatura proporcionou conforto térmico para as aves, na quinta semana de idade somente nos meses de março, abril, outubro e novembro a temperatura proporcionou conforto térmico para as aves. Nesta mesma fase de vida das aves as temperaturas apresentaram desconforto durante os meses de janeiro, fevereiro e dezembro, na sexta semana de idade nos meses de outubro a abril a temperatura proporcionou desconforto para as aves necessitando de um sistema de resfriamento. Com relação a umidade relativa média, verificamos que apresenta valores superiores aos ideais em todas as fases do ciclo de vida das aves e durante todo o ano. 
SILVA, E.T. et. al. Diagnóstico bioclimático para mesorregião...

TABELA 3 - Temperatura média e umidade relativa para microrregião de Antonina.

\begin{tabular}{|c|c|c|c|c|c|c|c|}
\hline \multirow[b]{3}{*}{ Meses do ano } & \multicolumn{6}{|c|}{ Temperaturas } & \multirow[t]{2}{*}{ UR } \\
\hline & \multicolumn{6}{|c|}{ Idade das Aves em Semanas } & \\
\hline & 1 & 2 & 3 & 4 & 5 & 6 & \\
\hline Janeiro & I & 1 & I & I & 1 & C & $\underline{S}$ \\
\hline Fevereiro & I & I & I & I & I & C & $\underline{S}$ \\
\hline Março & I & I & I & I & I & 1 & $\underline{S}$ \\
\hline Abril & I & I & I & I & I & 1 & $\underline{S}$ \\
\hline Maio & I & 1 & I & I & I & 1 & $\underline{S}$ \\
\hline Junho & I & 1 & I & I & I & I & $\underline{S}$ \\
\hline Julho & I & I & I & I & I & 1 & $\underline{S}$ \\
\hline Agosto & I & 1 & I & I & I & I & $\underline{S}$ \\
\hline Setembro & I & 1 & I & I & I & I & $\underline{S}$ \\
\hline Outubro & I & I & I & I & I & I & $\underline{S}$ \\
\hline Novembro & I & 1 & I & I & I & I & $\underline{S}$ \\
\hline Dezembro & 1 & 1 & 1 & 1 & 1 & C & $\underline{S}$ \\
\hline
\end{tabular}

TABELA 4 - Temperatura média e umidade relativa para microrregião de Cerro Azul.

\begin{tabular}{|c|c|c|c|c|c|c|c|}
\hline \multirow[b]{3}{*}{ Meses do ano } & \multicolumn{6}{|c|}{ Temperaturas } & \multirow[t]{2}{*}{ UR } \\
\hline & \multicolumn{6}{|c|}{ Idade das Aves em Semanas } & \\
\hline & 1 & 2 & 3 & 4 & 5 & 6 & \\
\hline Janeiro & 1 & I & I & C & $\mathrm{S}$ & $S$ & $\underline{S}$ \\
\hline Fevereiro & I & I & I & C & S & $S$ & $\underline{S}$ \\
\hline Março & 1 & I & I & C & C & $S$ & $\underline{S}$ \\
\hline Abril & 1 & I & 1 & I & C & $\mathrm{S}$ & $\underline{S}$ \\
\hline Maio & 1 & I & I & I & I & I & $\underline{S}$ \\
\hline Junho & 1 & I & I & I & I & I & $\underline{S}$ \\
\hline Julho & 1 & I & I & I & I & I & $\underline{S}$ \\
\hline Agosto & I & I & I & I & I & I & $\underline{S}$ \\
\hline Setembro & I & I & I & I & I & I & $\underline{S}$ \\
\hline Outubro & 1 & I & I & I & C & $S$ & $\underline{S}$ \\
\hline Novembro & 1 & I & I & I & C & $S$ & $\underline{S}$ \\
\hline Dezembro & 1 & I & I & C & $\mathrm{S}$ & $\mathrm{S}$ & $\underline{S}$ \\
\hline
\end{tabular}

\section{Microrregião de Guaraqueçaba}

Analisando as Tabelas 2 e 5 correspondente à temperatura e umidade relativa doar ideais para criação das aves e a temperatura média e umidade relativa, na sexta semana de idade, somente no mês de outubro a temperatura proporcionou conforto térmico para as aves e acima do limite de conforto durante os meses de novembro a abril. Na quinta semana de idade, somente nos meses de abril, outubro e novembro a temperatura proporcionou conforto térmico para as aves e acima dos limites de conforto durante os meses de dezembro a março. Na quarta semana de idade, somente nos meses de dezembro a março a temperatura proporcionou conforto térmico para as aves. Nos demais meses do ano a temperatura foi inferior ao exigido pelas aves em todas as fases de criação. Com relação à umidade relativa média, verificamos que apresenta valores superiores aos ideais em todas as fases do ciclo de vida das aves e durante todo o ano.

\section{Microrregião da Lapa}

Analisando as Tabelas 2 e 6 correspondente à temperatura e umidade relativa do ar ideais para criação das aves e a temperatura média e umidade relativa podemos verificar que na sexta e quinta semana de idade, somente nos meses de janeiro, fevereiro e dezembro a temperatura proporcionou conforto térmico para as aves. Nos demais meses do ano a temperatura ambiente foi inferior ao exigido pelas aves em todas as fases de criação. Com relação a umidade relativa média, verificamos que apresenta valores superiores aos ideais em todas as fases do ciclo de vida das aves e durante todo o ano.

\section{Microrregião de Morretes}

Analisando as Tabelas 2 e 7 correspondente à temperatura e umidade relativa do ar ideais para criação das aves e a temperatura média e umidade relativa podemos verificar que na sexta semana de idade, somente durante o mês de 
SILVA, E.T. et. al. Diagnóstico bioclimático para mesorregião...

TABELA 5 - Temperatura média e umidade relativa para microrregião de Guaraqueçaba.

\begin{tabular}{|c|c|c|c|c|c|c|c|}
\hline \multirow[b]{3}{*}{ Meses do ano } & \multicolumn{6}{|c|}{ Temperaturas } & \multirow[t]{2}{*}{ UR } \\
\hline & \multicolumn{6}{|c|}{ Idade das Aves em Semanas } & \\
\hline & 1 & 2 & 3 & 4 & 5 & 6 & \\
\hline Janeiro & 1 & 1 & I & C & $\mathrm{S}$ & $\mathrm{S}$ & $\underline{S}$ \\
\hline Fevereiro & 1 & 1 & I & C & $\mathrm{S}$ & $\mathrm{S}$ & $\underline{S}$ \\
\hline Março & I & 1 & I & C & $S$ & S & $\underline{S}$ \\
\hline Abril & 1 & 1 & I & I & C & S & $\underline{S}$ \\
\hline Maio & 1 & 1 & I & I & 1 & I & $\bar{S}$ \\
\hline Junho & 1 & I & I & I & 1 & I & $\underline{S}$ \\
\hline Julho & 1 & 1 & I & I & I & I & $\underline{S}$ \\
\hline Agosto & I & I & I & I & 1 & I & $\underline{S}$ \\
\hline Setembro & 1 & I & I & I & 1 & I & $\underline{S}$ \\
\hline Outubro & I & I & I & I & C & C & $\underline{S}$ \\
\hline Novembro & 1 & I & I & I & C & $S$ & $\underline{S}$ \\
\hline Dezembro & 1 & 1 & 1 & C & $\mathrm{S}$ & $\mathrm{S}$ & $\underline{S}$ \\
\hline
\end{tabular}

outubro a temperatura proporcionou conforto térmico para as aves, proporcionou desconforto do mês de novembro ao mês de abril. Na quinta semana de idade, somente nos meses de janeiro, fevereiro, março, outubro e novembro a temperatura proporcionou conforto térmico para as aves e desconforto no mês de dezembro. Na quarta semana de idade, durante os meses de dezembro a março a temperatura proporcionou conforto térmico para as aves. Nos demais meses do ano a temperatura ambiente foi inferior ao exigido pelas aves em todas as fases de criação. Com relação a umidade relativa média, verificamos que apresenta valores superiores aos ideais em todas as fases do ciclo de vida das aves e durante todo o ano.

\section{Microrregião de Pinhais}

Analisando as Tabelas 2 e 8 correspondente à temperatura e umidade relativa do ar ideais para criação das aves e a temperatura média e umidade relativa pode-se verificar que na

sexta e quinta semana de idade, somente nos meses de janeiro, fevereiro e dezembro a temperatura proporcionou conforto térmico para as aves. Nos demais meses do ano a temperatura ambiente foi inferior ao exigido pelas aves em todas as fases de criação. Com relação a umidade relativa média, verificamos que apresenta valores superiores aos ideais em todas as fazes do ciclo de vida das aves e durante todo o ano.

\section{CONCLUSÕES}

Todas as microrregiões apresentam temperaturas inferiores às de conforto térmico para aves durante as três primeiras semanas de vida;

As microrregiões de Antonina, Lapa e Pinhais não apresentam condições ideais para desenvolvimento da atividade durante todas as fases de vida, portanto, para tal exige investimentos em controle ambiental, ou seja, aquecimento contínuo do galpão de criação;

As microrregiões de Cerro Azul e Guaraqueçaba exigem sistemas de controle ambiental, aquecimento e principalmente resfriamento na última semana de vida;

Uma análise econômica e detalhada deve ser feita, para verificar a viabilidade econômica, pois os custos com controle ambiental, aquecimento e/ ou resfriamento podem levar a inviabilidade do projeto.

\section{REFERÊNCIAS}

1. ABEF - ASSOCIAC̄̃O BRASILEIRA DOS PRODUTORES E EXPORTADORES DE FRANGOS. Relatório Anual 2006. Disponível em: <http://www.abef.com.br/portal/_clientes/abef/cat/Relatorio_2006_9062.pdf>. Acesso em: 15/12/ 2007.

2. ABREU; V. M. N.; ABREU, P. G. Diagnóstico bioclimático para a produção de aves no Oeste paranaense. In: CONGRESSO BRASILEIRO DE ENGENHARIAAGRÍCOLA, 30., 2001. Anais... Foz do Iguaçu: UNIOESTE/SBEA, 2001. 1 CD-ROM.

3. LIN, H.; JIAO, H. C.; BUYSE, J.; DECUYPERE, E. Strategies for prevent heat stress in poultry. World's Poultry Sciense Journal, v. 62, p. 71-85, 2006.

4. $\quad$ PRODUCAO ANIMAL-AVICULTURA. Produção e mercado em resumo. Ano 2, n. 11, p. 22-23, mar. 2008.

5. SECEX - Secretaria de Comercio Exterior. Balança Comercial Brasileira - Dezembro 2007. Disponível em: <http://www2.desenvolvimento.gov.br/arquivo/secex/balanca/balcombrasileira/semanal/download.zip >. Acesso em:13/04/2008.

6. SILVA, M. A. N.; SILVA, I. J. O.; PIEDADE, S. M. S.; MARTINS, E.; COELHO, A. A. D.; SAVINO, V. J. M. Resistência ao estresse calórico em frangos de corte de pescoço pelado. Revista Brasileira de Ciência Avícola, v. 3, n. 1, p. 2733, 2001.

Recebido em 12/04/2004 Aceito em 04/09/2008 
SILVA, E.T. et. al. Diagnóstico bioclimático para mesorregião...

TABELA 6 - Temperatura média e umidade relativa para microrregião da Lapa.

\begin{tabular}{|c|c|c|c|c|c|c|c|}
\hline \multirow[b]{3}{*}{ Meses do ano } & \multicolumn{6}{|c|}{ Temperaturas } & \multirow[t]{2}{*}{ UR } \\
\hline & \multicolumn{6}{|c|}{ Idade das Aves em Semanas } & \\
\hline & 1 & 2 & 3 & 4 & 5 & 6 & \\
\hline Janeiro & 1 & 1 & 1 & I & C & C & $\underline{S}$ \\
\hline Fevereiro & 1 & I & I & I & C & C & $\underline{S}$ \\
\hline Março & 1 & 1 & I & I & I & 1 & $\underline{S}$ \\
\hline Abril & I & I & I & I & 1 & I & $\underline{S}$ \\
\hline Maio & $\mathrm{I}$ & 1 & I & I & 1 & I & $\underline{S}$ \\
\hline Junho & I & 1 & I & I & 1 & I & $\underline{S}$ \\
\hline Julho & I & 1 & I & I & I & I & $\underline{S}$ \\
\hline Agosto & I & I & I & I & 1 & I & $\underline{S}$ \\
\hline Setembro & I & I & I & I & I & I & $\underline{S}$ \\
\hline Outubro & I & 1 & I & I & I & I & $\underline{S}$ \\
\hline Novembro & I & I & I & I & 1 & I & $\underline{S}$ \\
\hline Dezembro & 1 & 1 & 1 & $\mathrm{I}$ & C & C & $\underline{S}$ \\
\hline
\end{tabular}

TABELA 7 - Temperatura média e umidade relativa para microrregião de Morretes.

\begin{tabular}{|c|c|c|c|c|c|c|c|}
\hline \multirow[b]{3}{*}{ Meses do ano } & \multicolumn{6}{|c|}{ Temperaturas } & \multirow[t]{2}{*}{ UR } \\
\hline & \multicolumn{6}{|c|}{ Idade das Aves em Semanas } & \\
\hline & 1 & 2 & 3 & 4 & 5 & 6 & \\
\hline Janeiro & 1 & I & 1 & C & $\mathrm{C}$ & $\mathrm{S}$ & $\underline{S}$ \\
\hline Fevereiro & I & I & I & C & C & $S$ & $\underline{S}$ \\
\hline Março & I & I & I & C & C & $\mathrm{S}$ & $\underline{S}$ \\
\hline Abril & I & I & I & I & I & $S$ & $\underline{S}$ \\
\hline Maio & I & I & I & I & I & I & $\underline{S}$ \\
\hline Junho & I & I & I & I & 1 & I & $\underline{S}$ \\
\hline Julho & I & I & I & I & 1 & I & $\underline{S}$ \\
\hline Agosto & I & I & I & I & I & I & $\underline{S}$ \\
\hline Setembro & I & I & I & I & 1 & 1 & $\underline{S}$ \\
\hline Outubro & I & I & I & I & C & C & $\underline{S}$ \\
\hline Novembro & I & I & I & I & C & $S$ & $\underline{S}$ \\
\hline Dezembro & 1 & 1 & 1 & C & $\mathrm{S}$ & $\mathrm{S}$ & $\underline{S}$ \\
\hline
\end{tabular}

TABELA 8 - Temperatura média e umidade relativa para microrregião de Pinhais.

\begin{tabular}{|c|c|c|c|c|c|c|c|}
\hline \multirow[b]{3}{*}{ Meses do ano } & \multicolumn{6}{|c|}{ Temperaturas } & \multirow[t]{2}{*}{$\cup R$} \\
\hline & \multicolumn{6}{|c|}{ Idade das Aves em Semanas } & \\
\hline & 1 & 2 & 3 & 4 & 5 & 6 & \\
\hline Janeiro & 1 & 1 & 1 & 1 & C & $\mathrm{C}$ & $\underline{S}$ \\
\hline Fevereiro & I & I & I & I & C & C & $\underline{S}$ \\
\hline Março & I & I & 1 & I & I & 1 & $\underline{S}$ \\
\hline Abril & I & I & I & $\mathrm{I}$ & I & 1 & $\underline{S}$ \\
\hline Maio & I & I & I & $\mathrm{I}$ & I & 1 & $\underline{S}$ \\
\hline Junho & I & I & I & $\mathrm{I}$ & $\mathrm{I}$ & 1 & $\underline{S}$ \\
\hline Julho & I & I & I & $\mathrm{I}$ & I & 1 & $\underline{S}$ \\
\hline Agosto & I & I & I & $\mathrm{I}$ & I & 1 & $\underline{S}$ \\
\hline Setembro & I & I & I & $\mathrm{I}$ & I & 1 & $\underline{S}$ \\
\hline Outubro & I & I & I & I & I & 1 & $\underline{S}$ \\
\hline Novembro & I & I & I & I & I & 1 & $\underline{S}$ \\
\hline Dezembro & $\mathrm{I}$ & 1 & 1 & $\mathrm{I}$ & C & $\mathrm{C}$ & $\underline{S}$ \\
\hline
\end{tabular}


